\title{
Activity of AMP2041 against human and animal multidrug resistant Pseudomonas aeruginosa clinical isolates
}

\author{
Clotilde Silvia Cabassi ${ }^{1}$, Andrea Sala ${ }^{1}$, Davide Santospirito ${ }^{1}$, Giovanni Loris Alborali ${ }^{2}$, Edoardo Carretto ${ }^{3}$, \\ Giovanni Ghibaudo ${ }^{4}$ and Simone Taddei ${ }^{1^{*}}$
}

\begin{abstract}
Background: Antimicrobial resistance is a growing threat to public health. Pseudomonas aeruginosa is a relevant pathogen causing human and animal infections, frequently displaying high levels of resistance to commonly used antimicrobials. The increasing difficulty to develop new effective antibiotics have discouraged investment in this area and only a few new antibiotics are currently under development. An approach to overcome antibiotic resistance could be based on antimicrobial peptides since they offer advantages over currently used microbicides.
\end{abstract}

Methods: The antimicrobial activity of the synthetic peptide AMP2041 was evaluated against 49 P. aeruginosa clinical strains with high levels of antimicrobial resistance, isolated from humans ( $n=19)$ and animals $(n=30)$. In vitro activity was evaluated by a microdilution assay for lethal dose $90 \%\left(L_{90}\right)$, while the activity over time was performed by time-kill assay with $12.5 \mu \mathrm{g} / \mathrm{ml}$ of AMP2014. Evidences for a direct membrane damage were investigated on P. aeruginosa ATCC 27853 reference strain, on animal isolate PA-VET 38 and on human isolate PA-H 24 by propidium iodide and on P. aeruginosa ATCC 27853 by scanning electron microscopy.

Results: AMP2041 showed a dose-dependent activity, with a mean (SEM) LD 90 of 1.69 and $3.3 \mu \mathrm{g} / \mathrm{ml}$ for animal and human strains, respectively. AMP2041 showed microbicidal activity on P. aeruginosa isolates from a patient with cystic fibrosis (CF) and resistance increased from first infection isolate ( $\mathrm{LD}_{90}=0.3 \mu \mathrm{g} / \mathrm{ml}$ ) to the mucoid phenotype $\left(\mathrm{LD}_{90}=10.4 \mu \mathrm{g} / \mathrm{ml}\right)$. The time-kill assay showed a time-dependent bactericidal effect of AMP2041 and LD $\mathrm{L}_{90}$ was reached within 20 min for all the strains. The stain-dead assay showed an increasing of membrane permeabilization and SEM analysis revealed holes, dents and bursts throughout bacterial cell wall after 30 min of incubation with AMP2041.

Conclusions: The obtained results assessed for the first time the good antimicrobial activity of AMP2041 on P. aeruginosa strains of human origin, including those deriving from a CF patient. We confirmed the excellent antimicrobial activity of AMP2041 on P. aeruginosa strains derived from dog otitis. We also assessed that AMP2041 antimicrobial activity is linked to changes of the P. aeruginosa cell wall morphology and to the increasing of membrane permeability.

Keywords: Antimicrobial peptide, Pseudomonas aeruginosa, Cinical isolates, Multidrug resistance, Bacterial membrane damage

\section{Background}

Pseudomonas aeruginosa is a relevant pathogen causing human and animal infections. In humans, severe $P$.

\footnotetext{
*Correspondence: simone.taddei@unipr.it

1 Department of Veterinary Science, University of Parma, Via del Taglio 10,

43126 Parma, Italy

Full list of author information is available at the end of the article
}

aeruginosa infections usually occur in immunocompromised patients and in nosocomial setting. P. aeruginosa infection often follow surgery or invasive procedures and causes mainly pneumonia and septicaemia. P. aeruginosa may also cause mild illnesses in healthy people, in which skin, ear and eye infections can occur. Moreover, $P$. aeruginosa is the major pathogen in the cystic fibrosis (CF). In CF, chronic P. aeruginosa infections occur in up to 
$85 \%$ of CF patients and the $P$. aeruginosa strains involved develop antibiotic resistance and phenotypic changes, from first infection to chronic infection and mucoid phenotype. These phenotypical changes could play a major role in the persistence of $P$. aeruginosa infections in CF patients [1]. Antibiotic resistance and the persistence of the organisms despite therapy once chronic infection has been established, is leading to the search for more effective therapeutic approaches [1].

Pseudomonas aeruginosa also cause diseases in both livestock and companion animals, including otitis and urinary tract infections in dogs, mastitis in dairy cows and endometritis in horses [2]. Resistance phenotypes are more frequent in dogs and multi-drug resistant (MDR) $P$. aeruginosa seem to emerge mainly in those suffering from otitis. Antimicrobial resistance in animal $P$. aeruginosa infections should be closely monitored in the future, in line with possible animal-to-human transfers between pets and owners [2]. P. aeruginosa is naturally resistant to many classes of drugs and its capacity to rapidly develop resistance during treatment is a frequent source of therapeutic failures. P. aeruginosa is one of the six ESKAPE pathogens, reported by the Infectious Diseases Society of America, that urgently require novel therapies [3]. Rates of antibiotic resistance in $P$. aeruginosa are increasing worldwide even if the true frequency of infections caused by MDR $P$. aeruginosa is difficult to estimate. A review of studies reporting on MDR, extensively-drug resistant (XDR) and pan-drug resistant (PDR) P. aeruginosa infections revealed that aminoglycosides, antipseudomonal penicillins, cephalosporins, carbapenems and fluoroquinolones [4] have become ineffective as first line agents. The multidrug resistance of $P$. aeruginosa could be mediated by several mechanisms including multidrug efflux systems, enzyme production, outer membrane protein loss and target mutations [5]. The spread of antimicrobial resistance increase human and animal health hazard worldwide, thus makes mandatory the investigation of novel approaches to cover the therapeutic shortfall. In this view, one of the actions put forward in the European Commission Action Plan is to develop effective antimicrobials or alternatives for treatment of human and animal infections and to reinforce research to develop innovative means to combat antimicrobial resistance [6]. Antimicrobial peptides offer potential advantages over currently used classes of drugs. They may counteract pathogenic challenge by rapid, broad spectrum, microbicidal activity [7], targeting multiple pathogens with one treatment. Moreover, antimicrobial peptides may have the potential to ultimately reduce the rate of emergence of resistant microorganisms, since selective pressure is not focused to a single specific molecular target. Further, antimicrobial peptides could also be potentially used in conjunction with conventional antibiotics as part of a "combination therapy" to create an additive or synergistic effect.

The antimicrobial peptide AMP2041 is a cyclic antimicrobial peptide, belonging to a novel family of antimicrobial cationic peptides, which showed good antimicrobial activity against a panel of different Gram-positive and Gram-negative bacterial pathogens of animal origin [8]. The activity of AMP2041 against P. aeruginosa ATCC 27853 was also demonstrated, as well as additivity in combination with levofloxacin [9]. We hypothesized that the reported antimicrobial activity derived from a bacterial membrane damage, but a direct membrane damage was not previously investigated for $P$. aeruginosa.

The aim of the present work was to evaluate the antimicrobial activity of AMP2041 on different MDR, PDR and XDR $P$. aeruginosa clinical isolates of human origin, including five different phenotypes of $P$. aeruginosa derived from a single patient with cystic fibrosis, and on clinical MDR $P$. aeruginosa clinical isolates deriving from animals, mainly dogs with otitis. Further, we investigated the evidence for a direct membrane damage on P. aeruginosa ATCC 27853 reference strain.

\section{Methods}

\section{Bacterial strains and antibiotic susceptibility}

Isolates and their biochemical profiles, obtained by API System (bioMérieux, Marcy l'Etoile, France), are reported in Tables 1, 2 and 3. Antibiotic susceptibility tests were performed using the system Vitek2 (bioMérieux, Marcy l'Etoile, France) and/or the Kirby-Bauer method (antibiotic disks provided by Mast Diagnostics Germany, Oxoid, UK). P. aeruginosa drug-resistant strains were defined following the European Centre for Disease Prevention and Control (ECDC) guidelines [10]. The following

Table 1 Pseudomonas aeruginosa human clinical isolates

\begin{tabular}{llllll}
\hline $\begin{array}{l}\text { Reference } \\
\text { number }\end{array}$ & ID number & Source & API20E & Sample & $\begin{array}{l}\text { Resistance } \\
\text { profile }\end{array}$ \\
\hline$[1]$ & PA-H 1 & Human & 2216004 & Urine & XDR \\
{$[2]$} & PA-H 10 & Human & 2217046 & Blood & MDR \\
{$[3]$} & PA-H 24 & Human & 2216046 & Blood & XDR \\
{$[4]$} & PA-H 25 & Human & 2206046 & Urine & MDR \\
{$[5]$} & PA-H 37 & Human & 2206046 & Blood & MDR \\
{$[6]$} & PA-H 45 & Human & 2210004 & Urine & MDR \\
{$[7]$} & PA-H 47 & Human & 2217046 & Blood & MDR \\
{$[8]$} & PA-H 52 & Human & 2206006 & Blood & MDR \\
{$[9]$} & PA-H 56 & Human & 2206046 & Blood & XDR \\
{$[10]$} & PA-H 58 & Human & 2206006 & Blood & MDR \\
{$[11]$} & PA-H 71 & Human & 2206046 & Blood & MDR \\
{$[12]$} & PA-H 37/2 & Human & 2206006 & Blood & MDR \\
{$[13]$} & PA-H 45/2 & Human & 2206006 & Urine & MDR \\
{$[14]$} & PA-H 14 & Human & 2206046 & Blood & MDR \\
\hline
\end{tabular}


Table 2 Pseudomonas aeruginosa clinical isolates obtained from a single cystic fibrosis (CF) patient

\begin{tabular}{|c|c|c|c|c|c|}
\hline Reference number & ID number & Source & API20E & Sample & Resistance profile \\
\hline [1] & $\begin{array}{l}\text { PA-H 1PE } \\
\text { (first infection) }\end{array}$ & Human & 2206006 & Sputum & Non-MDR \\
\hline [2] & $\begin{array}{l}\text { PA-H 2PCa } \\
\text { (mucoid phenotype) }\end{array}$ & Human & 2216004 & Sputum & Non-MDR \\
\hline [3] & $\begin{array}{l}\text { PA-H 3BFa } \\
\text { (chronic infection) }\end{array}$ & Human & 2206046 & Sputum & $X D R$ \\
\hline [4] & $\begin{array}{l}\mathrm{PA}-\mathrm{H} \text { 3BFb } \\
\text { (chronic infection) }\end{array}$ & Human & 2217046 & Sputum & XDR \\
\hline [5] & $\begin{array}{l}\text { PA-H 3BFC } \\
\text { (chronic infection) }\end{array}$ & Human & 2206046 & Sputum & XDR \\
\hline
\end{tabular}

Table 3 Pseudomonas aeruginosa animal clinical isolates

\begin{tabular}{|c|c|c|c|c|c|}
\hline Reference number & ID number & Source & API20E & Sample & Resistance profile \\
\hline [1] & PA-VET 7 & Dog & 2206006 & Auricular swab & MDR \\
\hline [2] & PA-VET 9 & Dog & 2202001 & Auricular swab & MDR \\
\hline [3] & PA-VET 10 & Dog & 2216046 & Auricular swab & MDR \\
\hline [4] & PA-VET 11 & Dog & 2206046 & Auricular swab & MDR \\
\hline [5] & PA-VET 13 & Dog & 2206046 & Liver & MDR \\
\hline [6] & PA-VET 15A & Dog & 2206006 & Auricular swab & MDR \\
\hline [7] & PA-VET 15B & Dog & 2212004 & Auricular swab & MDR \\
\hline [8] & PA-VET 16 & Dog & 2206046 & Auricular swab & MDR \\
\hline [9] & PA-VET 17 & Dog & 2206046 & Urine & MDR \\
\hline [10] & PA-VET 18 & Dog & 2206046 & Auricular swab & MDR \\
\hline [11] & PA-VET 19 & Dog & 2206046 & Auricular swab & MDR \\
\hline [12] & PA-VET $20 \mathrm{~A}$ & Dog & 2206006 & Urine & MDR \\
\hline [13] & PA-VET 20B & Dog & 2216004 & Auricular swab & MDR \\
\hline [14] & PA-VET 22 & Dog & 2206046 & Auricular swab & MDR \\
\hline [15] & PA-VET 23 & Dog & 2206006 & Auricular swab & MDR \\
\hline [16] & PA-VET 24 & Dog & 2206046 & Foreskin swab & MDR \\
\hline [17] & PA-VET 26 & Dog & 2216046 & Auricular swab & MDR \\
\hline [18] & PA-VET 27 & Dog & 2217046 & Auricular swab & MDR \\
\hline [19] & PA-VET 28 & Dog & 2206046 & Auricular swab & MDR \\
\hline [20] & PA-VET 29 & Dog & 2206046 & Auricular swab & MDR \\
\hline [21] & PA-VET 30 & Dog & 2206006 & Auricular swab & MDR \\
\hline$[22]$ & PA-VET 31 & Dog & 2206046 & Auricular swab & MDR \\
\hline [23] & PA-VET 32 & Dog & 2206006 & Auricular swab & MDR \\
\hline [24] & PA-VET 33 & Dog & 2212046 & Auricular swab & MDR \\
\hline [25] & PA-VET 34 & Dog & 2206006 & Auricular swab & MDR \\
\hline [26] & PA-VET 35A & Dog & 2212046 & Foreskin swab & MDR \\
\hline [27] & PA-VET 35B & Dog & 2210004 & Auricular swab & MDR \\
\hline [28] & PA-VET 36 & Dog & 2206006 & Auricular swab & MDR \\
\hline [29] & PA-VET 37 & Dog & 2206006 & Auricular swab & MDR \\
\hline [30] & PA-VET 38 & Dog & 2210004 & Auricular swab & MDR \\
\hline
\end{tabular}

classes of antimicrobials were tested: aminoglycosides, carbapenems, cephalosporins, fluoroquinolones, penicillins, monobactams, phosphonic acids, polymyxins. The resistance profiles of the isolates are reported in Tables 1 , 2 and 3.

\section{Peptide}

The peptide AMP2041 used in this study was developed as described elsewhere [9], and synthesized from SelleckChem (Houston, TX, USA). The purity ( $>98 \%)$, sequence and concentration of the peptide were determined and 
verified by SelleckChem by using high pressure liquid chromatography (HPLC) and mass spectroscopy. The peptide was dissolved in phosphate buffer $(\mathrm{PB})(10 \mathrm{mM}$, $\left.0.8709 \mathrm{~g} / \mathrm{l} \mathrm{K}{ }_{2} \mathrm{HPO}_{4}, 0.6804 \mathrm{~g} / \mathrm{KH}_{2} \mathrm{PO}_{4}, \mathrm{pH} 7.0\right)$ at the concentration of $1 \mathrm{mg} / \mathrm{ml}$.

\section{Antibacterial activity evaluation}

Methods were described in detail elsewhere [9]. Briefly, bacterial suspension was prepared in PB $10 \mathrm{mM}$ measuring spectrophotometrically the absorbance at $600 \mathrm{~nm}$ to a concentration of $10^{8}$ colony-forming units (CFU)/ $\mathrm{ml}$. The adjusted bacterial suspension was then diluted to obtain a final concentration of bacteria of approximately $5 \times 10^{5} \mathrm{CFU} / \mathrm{ml}$. Serial dilutions of peptide were performed in a microtiter plate so that final concentrations were within the range $0.4-100 \mu \mathrm{g} / \mathrm{ml}$. After bacterial suspension addition, microtiter plates were incubated for $2 \mathrm{~h}$ at $37^{\circ} \mathrm{C}$. Then, $20 \mu \mathrm{l}$ of each dilution were plated onto tryptose agar containing $5 \%$ bovine erythrocytes. After $24 \mathrm{~h}$ of incubation at $37^{\circ} \mathrm{C}$, the colonies were counted. The minimal bactericidal concentration (MBC) was the lowest concentration of peptide that killed $>99.9 \%$ of bacteria, while lethal dose $90 \%\left(\mathrm{LD}_{90}\right)$ was the concentration of peptide that killed $90 \%$ of bacteria.

\section{Time-kill assay}

To evaluate the bactericidal kinetic, $5 \times 10^{5} \mathrm{CFU} / \mathrm{ml}$ of $P$. aeruginosa were incubated with $12.5 \mu \mathrm{g} / \mathrm{ml}$ of AMP2041 at $37^{\circ} \mathrm{C}$ in PB. The concentration of $12.5 \mu \mathrm{g} / \mathrm{ml}$ was chosen because it represents the minimal concentration of peptide capable to kill all the tested bacterial strains. Moreover, the same concentration was used for the time-kill assay performed in a previous work on P. aeruginosa ATCC 27853 [9]. Aliquots of $20 \mu \mathrm{l}$ were withdrawn at different intervals (every $5 \mathrm{~min}$ until $30 \mathrm{~min}$, then every $10 \mathrm{~min}$ until $60 \mathrm{~min}$, then every $30 \mathrm{~min}$ until $120 \mathrm{~min}$ ) and plated onto tryptose agar containing $5 \%$ bovine erythrocytes. After overnight incubation at $37^{\circ} \mathrm{C}$, the $\mathrm{CFU}$ were counted. Controls were performed in $\mathrm{PB}$ without peptide.

\section{Permeation of the bacterial inner membrane}

To assess the ability of antimicrobial peptides to alter the permeability of the inner membrane (IM) of $P$. aeruginosa, a dead-cell stain procedure, using the cationic DNA-staining dye propidium iodide (PI) (Invitrogen, Carlsbad, CA, USA), was performed. PI is unable to permeate the membranes and therefore does not enter viable cells with intact membranes. In dead cells PI gain access to nucleic acids, intercalates between the bases and red fluorescence increases. The stain-dead assay was performed as described in a previous work
[11] using $10^{9} \mathrm{CFU} / \mathrm{ml}$ log-phase cultures of $P$. aeruginosa ATCC 27853, PA-H 24 and PA-VET 38 in the presence of $12.5 \mu \mathrm{g} / \mathrm{ml}$ of AMP2041 and of $3 \mu \mathrm{M}$ PI. After peptide addition, the fluorescence emission of PI was measured every $5 \mathrm{~min}$ up to $25 \mathrm{~min}$, by a fluorescence microscope (Nikon Eclipse 50i) at 1000×. 4',6-diamidino-2-phenylindole (DAPI) (Invitrogen, Carlsbad, CA, USA) was used for counterstaining (blue fluorescence). Negative and positive controls (not shown) were obtained in absence of peptide and in presence of $1 \mathrm{mM}$ ethylenediaminetetraacetic acid and $0.5 \%$ Triton X-100, respectively.

\section{Scanning electron microscopy analysis}

The test was performed on the $P$. aeruginosa ATCC 27853 reference strain. The cell/peptide ratio used for the scanning electron microscopy (SEM) assay was at least 20 times higher than in the conditions used to determine the MBC. After a contact time of 30 min with AMP2041, the bacterial pellet was obtained by centrifugation at $4000 \mathrm{~g}$ for $5 \mathrm{~min}$ and washed twice in $\mathrm{PB}, \mathrm{pH}$ 7.2. Bacteria were then fixed in a solution of $1 \%$ glutaraldehyde in $0.1 \mathrm{M}$ sodium cacodylate (Santa Cruz Biotech, Santa Cruz, CA) for $1 \mathrm{~h}$ and washed with water for $1 \mathrm{~h}$. Then, the bacteria were soaked again in water, and the pellet after centrifugation was dehydrated in a series of ethanol washes. Ten microliters of the bacterial suspension were then mounted and imaged.

\section{Results}

\section{Antibacterial activity evaluation}

The antibacterial activity of AMP2041 on the 49 clinical isolates of $P$. aeruginosa is shown in Fig. 1a, b. AMP2041 showed antibacterial activity against the tested clinical strains with an $\mathrm{LD}_{90}$ ranging from 1.69 to $3.3 \mu \mathrm{g} / \mathrm{ml}$ for animal and human strains, respectively (Table 4). The $\mathrm{LD}_{90}$ confidence interval 95\% estimated for animal isolates was more narrow $(1.14-2.25 \mu \mathrm{g} / \mathrm{ml})$ compared to human strains $(1.75-4.31 \mu \mathrm{g} / \mathrm{ml})$. The activity of AMP2041 against $P$. aeruginosa strains derived from a single patient affected by $\mathrm{CF}$ is reported in Table 4 and Fig. $1 \mathrm{~b}$.

For first infection strain (PA-H 1PE) we observed a value of $\mathrm{LD}_{90}$ less than $1 \mu \mathrm{g} / \mathrm{ml}$. For chronic infection strains (PA-H 3BFa, PA-H 3BFb and $\mathrm{PA}-\mathrm{H} 3 \mathrm{BFc}$ ) and mucoid phenotype strain (PA-H 2PCa), we observed a shift of $\mathrm{LD}_{90}$ towards higher values, ranging from 2.25 to $10.4 \mu \mathrm{g} / \mathrm{ml}$. In particular, the highest $\mathrm{LD}_{90}$ was observed for the mucoid phenotype $(10.4 \mu \mathrm{g} / \mathrm{ml})$. For chronic infection strains as well as for the mucoid phenotype strain, AMP2041 was able to kill all the bacteria at a concentration of $12.5 \mu \mathrm{g} / \mathrm{ml}$ (Fig. 1b). 


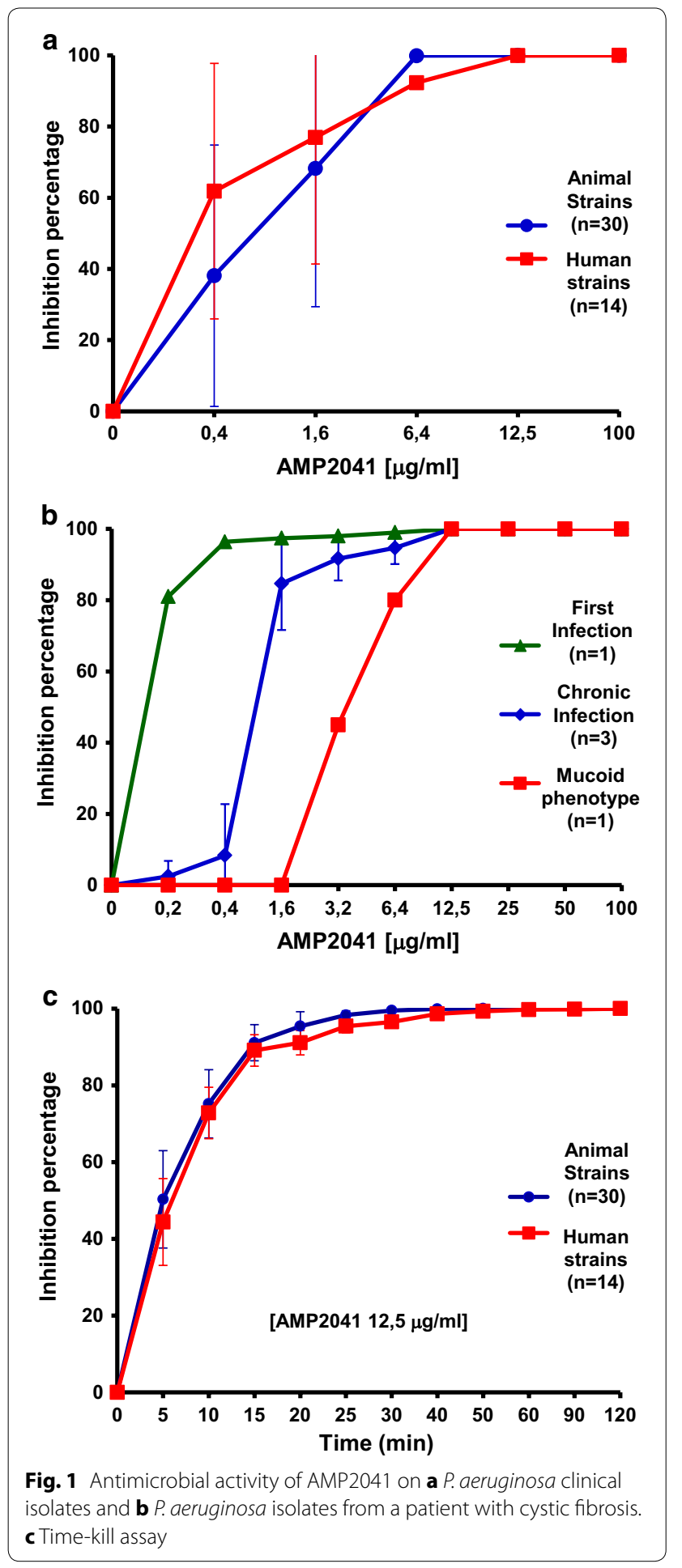

Time-kill assay

Inhibition percentages of AMP2041 over time on the 14 $P$. aeruginosa clinical human isolates and on the $30 P$.
Table 4 Antimicrobial activity of AMP2041 against PA isolates

\begin{tabular}{|c|c|c|c|}
\hline $\begin{array}{l}\text { Reference } \\
\text { number }\end{array}$ & $\begin{array}{l}\text { Human } \\
\text { clinical isolates } \\
\mathrm{LD}_{90}[\mu \mathrm{g} / \mathrm{ml}]\end{array}$ & $\begin{array}{l}\text { Cystic fibrosis } \\
\text { isolates } \\
\mathrm{LD}_{90}[\mu \mathrm{g} / \mathrm{ml}]\end{array}$ & $\begin{array}{l}\text { Animal } \\
\text { clinical isolates } \\
\mathrm{LD}_{90}[\mu \mathrm{g} / \mathrm{ml}]\end{array}$ \\
\hline [1] & 3.02 & 0.3 & 1.09 \\
\hline [2] & 1.03 & 10.4 & 8.30 \\
\hline [3] & 0.6 & 4.5 & 0.77 \\
\hline [4] & 1.14 & 3.8 & 0.93 \\
\hline [5] & 0.18 & 3.2 & 2.91 \\
\hline [6] & 6.07 & - & 2.87 \\
\hline [7] & 7.78 & - & 2.94 \\
\hline [8] & 3.77 & - & 1.75 \\
\hline [9] & 3.63 & - & 1.75 \\
\hline$[10]$ & 0.97 & - & 0.94 \\
\hline [11] & 2.14 & - & 2.80 \\
\hline [12] & 6.15 & - & 0.99 \\
\hline [13] & 0.95 & - & 2.33 \\
\hline [14] & 5.04 & - & 1.41 \\
\hline [15] & - & - & 1.06 \\
\hline [16] & - & - & 1.16 \\
\hline$[17]$ & - & - & 1.01 \\
\hline [18] & - & - & 0.56 \\
\hline [19] & - & - & 0.77 \\
\hline$[20]$ & - & - & 0.63 \\
\hline$[21]$ & - & - & 1.39 \\
\hline [22] & - & - & 0.98 \\
\hline [23] & - & - & 1.14 \\
\hline [24] & - & - & 0.36 \\
\hline$[25]$ & - & - & 2.15 \\
\hline [26] & - & - & 0.53 \\
\hline [27] & - & - & 2.87 \\
\hline [28] & - & - & 2.80 \\
\hline [29] & - & - & 0.51 \\
\hline [30] & - & - & 0.83 \\
\hline $\begin{array}{l}\text { Mean } \pm \text { SD } \\
{[95 \% \mathrm{Cl}]}\end{array}$ & $\begin{array}{l}3.3 \pm 2.44 \\
{[1.75-4.31]}\end{array}$ & $\begin{array}{l}4.44 \pm 3.31 \\
{[1.54-7.34]}\end{array}$ & $\begin{array}{l}1.69 \pm 1.5 \\
{[1.14-2.25]}\end{array}$ \\
\hline
\end{tabular}

aeruginosa clinical animal isolates are shown in Fig. 1c. A reduction of CFU count $>90 \%$ was observed within 20 min of incubation with peptide.

\section{Permeation of the bacterial inner membrane}

The stain-dead assay showed a clear red fluorescence after 10 min for $P$. aeruginosa ATCC 27853 and for the animal isolate PA-VET 38, whilst the presence of fluorescence for the human isolate PA-H 24 was not clearly evident before $15 \mathrm{~min}$ of incubation (Fig. 2). 


\section{Scanning electron microscopy analysis}

The SEM analysis was performed on the $P$. aeruginosa ATCC 27853 reference strain. The untreated bacteria displayed a smooth and intact surface (Fig. 3a) with typical rod morphology about $2 \mu \mathrm{m}$ long and $0.5 \mu \mathrm{m}$ wide. After incubation with AMP2041, bacteria showed several holes, multiple dents and bursts with deep craters throughout cell wall (Fig. 3b, c). Lysed cells and debris were also observed.

\section{Discussion}

Pseudomonas aeruginosa is an ubiquitous organism. Its ability to survive on minimal nutritional requirements and to tolerate a variety of physical conditions allows its persistence in both community and hospital settings [12]. $P$. aeruginosa is a serious therapeutic challenge for treatment of both community-acquired and nosocomial infections, due to the ability of this microorganism to develop resistance to multiple classes of antibacterial agents, even during the course of therapy [13, 14]. The increasing frequency of MDR or XDR P. aeruginosa strains is of concern as effective antimicrobial options are limited $[15,16]$. Moreover, only a few new antibiotics are currently under development [6]. An increase in MDR bacterial infections among companion animals has been documented in multiple veterinary hospital settings [17]. This is of particular importance due to the risk of transmission to humans and other companion animals in close contact with infected animals, even because in our countries the pet population continues to rise and the contacts between people and their companion animals grows stronger [18-20]. Therefore, the discover of new agents or innovative approaches able to counteract the growing problem of antimicrobial resistance become crucial.

The synthetic peptide AMP2041 is a cationic peptide and possesses a significant proportion of hydrophobic or non-polar residues. These structural features are common to many antimicrobial peptides $[9,21]$. The hydrophobic core is essential for the antimicrobial peptide to effectively permeate the bacterial membrane. The hydrophobic core is flanked at both ends by cationic and polar residues that help to solubilize the peptides in aqueous solution. Cationic and polar residues are also important for the initial electrostatic attraction of antimicrobial peptides to negatively charged phospholipid membranes of bacteria. Also the conformation assumed by AMP2041 might be responsible for the observed antimicrobial activity $[8,9,22]$.

Antimicrobial activity of AMP2041 on human clinical isolates was never investigated before. In this study we evaluated the activity of AMP2041 on 19 MDR or XDR $P$. aeruginosa strains isolated from different pathological conditions of humans, among which five deriving from a CF patient. Moreover, the activity of AMP2041 was tested on a sample of 30 MDR $P$. aeruginosa strains derived from dog otitis. AMP2041 showed an excellent activity against all the examined strains. In particular, on average, it was more effective against animals strains, with an $\mathrm{LD}_{90}$ of $1.69 \mu \mathrm{g} / \mathrm{ml}$ and an $\mathrm{MBC}$ of $6.4 \mu \mathrm{g} / \mathrm{ml}$ $(3.2 \mu \mathrm{M})$, compared with human strains, $\mathrm{LD}_{90}$ of $3.3 \mu \mathrm{g} /$ $\mathrm{ml}, \mathrm{MBC}$ of $12.5 \mu \mathrm{g} / \mathrm{ml}(6.2 \mu \mathrm{M})$. The antimicrobial activity found here for AMP2041 against $P$. aeruginosa is comparable or better than many highly-active antimicrobial peptides. Zhou et al. have found MIC values against $P$. aeruginosa ranging from 31 to $>256 \mu \mathrm{g} / \mathrm{ml}$ for peptides synthesized via ring-opening polymerization of $\alpha$-amino acid $N$-carboxyanhydrides [23]. Regarding the activity of Cecropin A, an insect antimicrobial peptide, against $P$. aeruginosa, a MIC value of $64 \mu \mathrm{g} / \mathrm{ml}$ is reported by Zhou et al. [23] and a lethal concentration of $3.5 \mu \mathrm{M}$ by Andreu et al. [24]. For PR-39, an antimicrobial peptide from pig intestine, a lethal concentration of $200 \mu \mathrm{M}$ against $P$. aeruginosa was reported [25]. Very recently, minimum lethal concentrations ranging from 3 to $100 \mu \mathrm{M}$ were reported for $E$. coli MreB derived antimicrobial peptides against $P$. aeruginosa [26].

It is noteworthy the antimicrobial activity of AMP2041 against the strains derived from the patient with CF. Most patients with CF become chronically infected with wild-type (first infection) $P$. aeruginosa strains early in their life. During the years following the initial colonization, the first infection strains may mutate into mucoid variants [27, 28]. Conversion to the mucoid phenotype is thought to be driven mainly by the unique CF microenvironment [28]. In our case, the $P$. aeruginosa mucoid strain was less sensitive to AMP2041 than the other tested CF strains (Fig. 1b). However, this result was obtained on a single strain and should be further investigated with a wider sample to confirm a higher resistance of the mucoid phenotype compared to the first and chronic infection isolates. The observed lower sensitivity to AMP2041 of the P. aeruginosa mucoid strain could be linked to the over production of mucoid exopolysaccharides that hide the negatively charged surface components to which positively charged peptides are attracted.

Mean MBC for dog strains $(\mathrm{n}=30, \mathrm{MBC}=6.4 \mu \mathrm{g}$ / $\mathrm{ml}-$ see Fig. 1a) is higher than values previously found for the reference strain ATCC $27853(4.35 \mu \mathrm{g} / \mathrm{ml})$ and other dog isolates $(\mathrm{n}=6, \mathrm{MBC}=2.44 \mu \mathrm{g} / \mathrm{ml})$ [8]. Therefore, the increased sample size allowed us to re-evaluate the $\mathrm{MBC}$ average value previously obtained.

The bacterial killing assay indicated a CFU reduction $>90 \%$ within $20 \mathrm{~min}$ (Fig. 1c). Therefore, the antimicrobial activity of AMP2041 occurs quickly and the killing kinetic profiles of human and animal clinical isolates, 


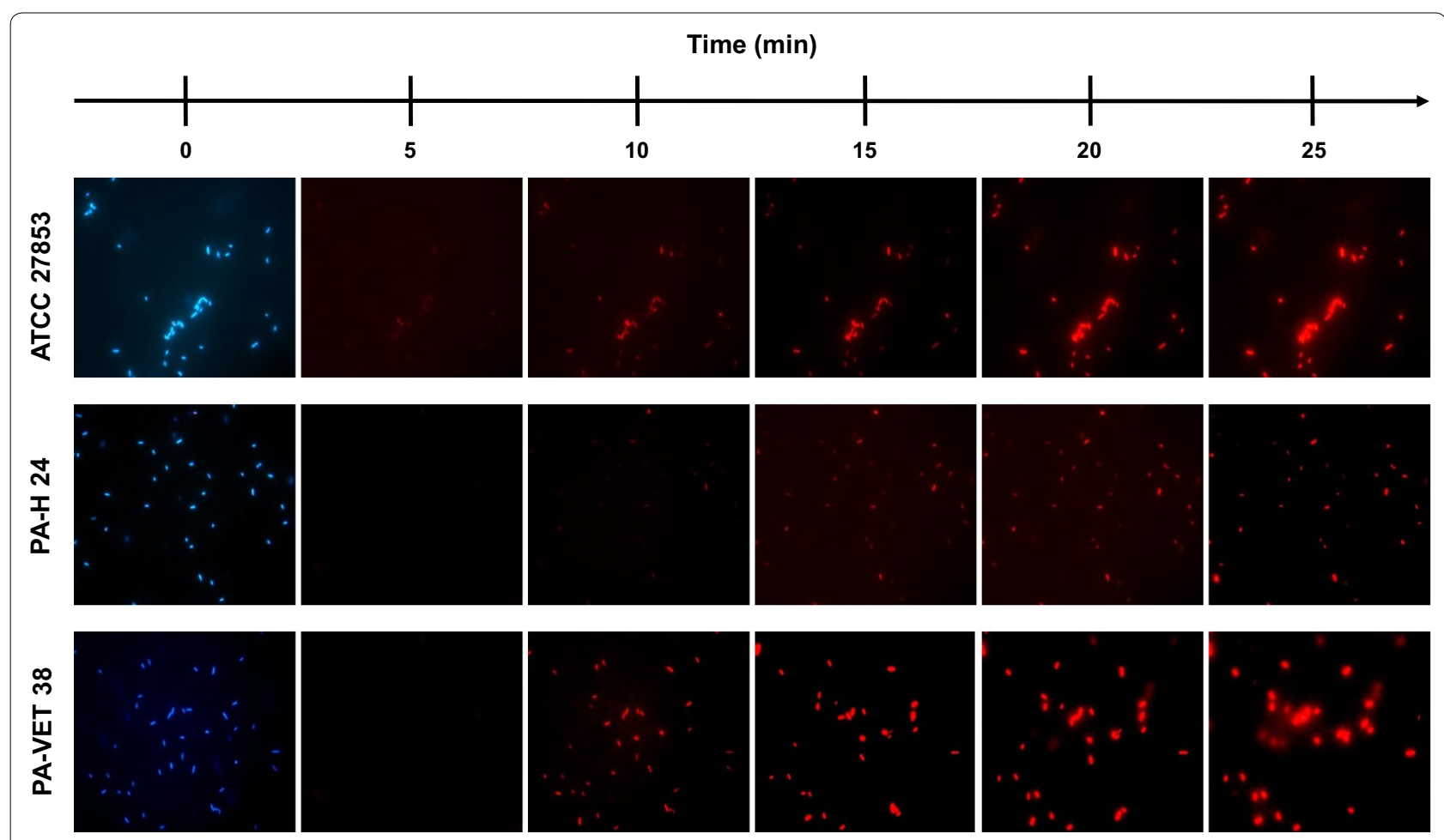

Fig. 2 Propidium iodide dead-cell stain assay: permeabilization of the inner membrane of P. aeruginosa strains following contact with AMP2041

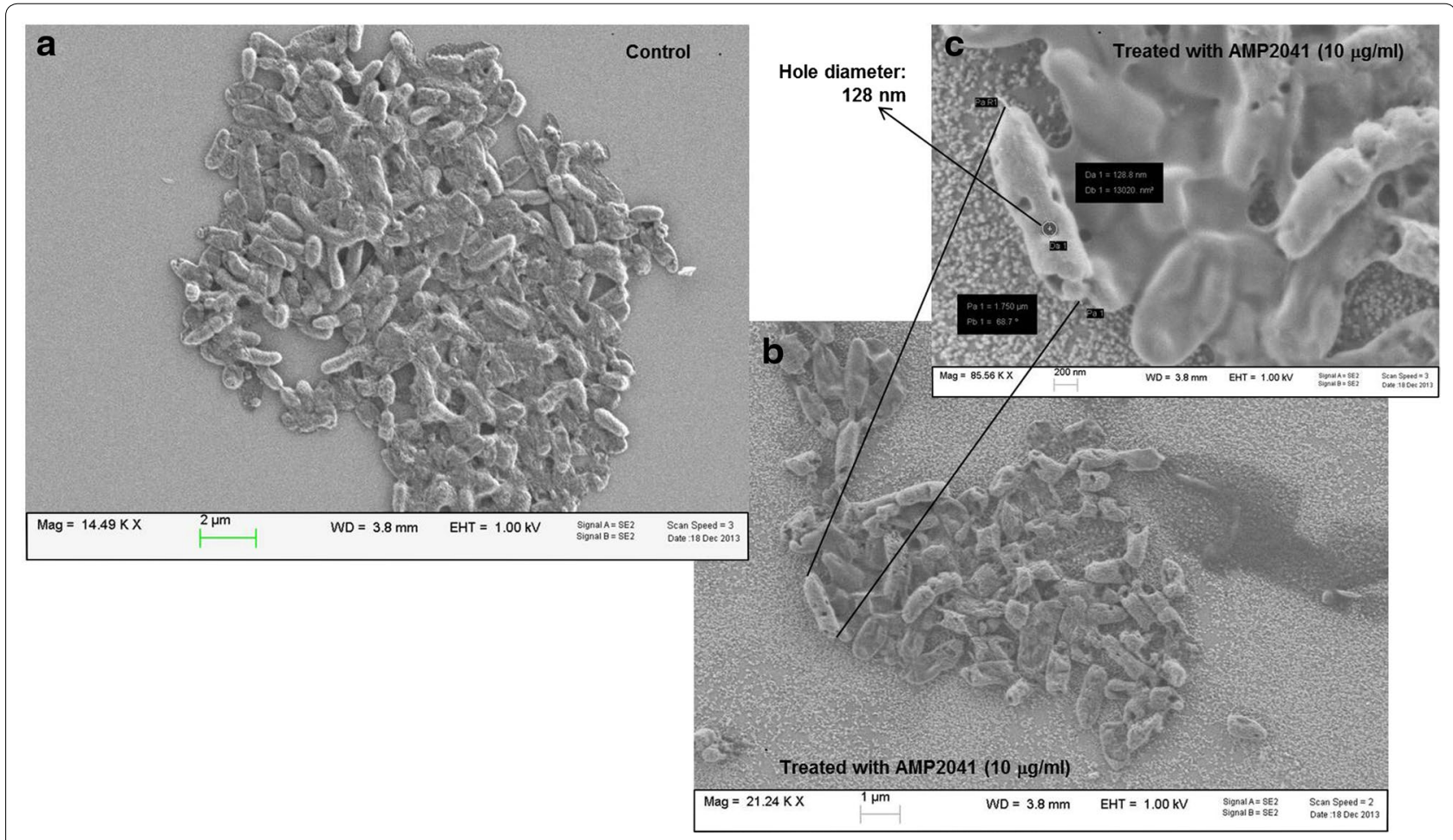

Fig. 3 SEM analysis performed on P. aeruginosa ATCC 27853. a Untreated; b treated with AMP2041; c holes size measurement 
never investigated before, were similar to that previously reported for $P$. aeruginosa ATCC $27853[8,9]$. These results were almost unrelated to the sources of strains, suggesting that the mechanism of action was similar for all the examined strains. The killing kinetics are comparable [29] or better [30] than those obtained with other established antimicrobial peptides at their lethal concentration. Saikia et al., instead, showed that two out of four $E$. coli MreB derived peptides completely killed $P$. aeruginosa within 5 min of treatment with the peptides at their minimum lethal concentrations [26]. However, in our case the kinetic of killing of AMP2041 was derived from the testing of many different $P$. aeruginosa strains, while in the other cases only one $P$. aeruginosa strain was tested. Moreover, an interesting fact that emerges from the work of Saikia et al. is that for $P$. aeruginosa there is no direct correlation between the minimum lethal concentration and the rapidity of killing, because the peptide with the best minimum lethal concentration $(3 \mu \mathrm{M})$ completely killed the bacteria only after $120 \mathrm{~min}$.

The stain-dead assay was performed on the $P$. aeruginosa ATCC 27853 reference strain and on PA-H 24 and PA-VET 38, which were selected for the assay as representative of strains with a high level of antibiotic resistance, being XDR and MDR (see Tables 1, 3), respectively. Results indicated that the inhibitory effect of AMP2041 is linked to an altered permeability of the cellular membrane of P. aeruginosa (Fig. 2). This is in accordance with the mechanism of action of cationic antimicrobial peptides which cause cell death through loss of membrane integrity [22]. The timing of the occurrence of red fluorescence was in accordance with time kill results. The membrane damage was evident within $10 \mathrm{~min}$ of incubation for the reference strain and the animal isolate PA-VET 38 and within 15 min for the human isolate PA-H 24.

To confirm that the fluorescence increase was due to morphological changes of bacterial membrane, a SEM analysis was performed on the $P$. aeruginosa ATCC 27853 reference strain treated with AMP2041. SEM analysis provided evidence for a direct membrane damage, showing the presence of several holes, dents and bursts throughout cell wall (Fig. 3b, c). Similar membrane changes are also described for other cationic antimicrobial peptides $[23,26,31]$. The microbicidal effect of AMP2041 was also confirmed by the presence of lysed cells.

\section{Conclusions}

In conclusion, we assessed the good antimicrobial activity of AMP2041 on P. aeruginosa strains of human origin, including those deriving from a CF patient. Moreover, we confirmed the excellent antimicrobial activity of AMP2041 on P. aeruginosa strains derived from dog otitis. We also assessed that AMP2041 antimicrobial activity is linked to changes of the $P$. aeruginosa cell wall morphology and the increasing of membrane permeability. This mechanism of action is less prone to induce resistance by the pathogen compared to antimicrobials acting against intracellular targets. However, clinical trials with adequate animal models should be performed to define the therapeutic potential of AMP2041.

\section{Abbreviations \\ CF: cystic fibrosis; CFU: colony-forming unit; DAPI: 4',6-diamidino-2-phenylin- dole; ECDC: European Centre for Disease Prevention and Control; EDTA: ethyl- enediaminetetraacetic acid; ESKAPE: Enterococcus faecium (E) Staphylococcus aureus (S) Klebsiella pneumoniae (K) Acinetobacter baumannii (A) Pseudomonas aeruginosa (P) Enterobacter Species (E); HPLC: high pressure liquid chroma- tography; IM: inner membrane; LD: lethal dose; MBC: minimal bactericidal concentration; MDR: multi-drug resistant; PA-H: Pseudomonas aeruginosa, human isolate; PA-VET: Pseudomonas aeruginosa, animal isolate; PB: phosphate buffer; PDR: pan-drug resistant; PI: propidium iodide; SEM: scanning electron microscopy; XDR: extensively-drug resistant.}

\section{Authors' contributions}

CSC and ST were involved in all aspects of this study including data collection, analysis and manuscript preparation. AS and DS carried out the laboratory studies. GLA and GG collected and analysed animal strains. EC collected and analysed human strains. All authors read and approved the final manuscript.

\section{Author details}

${ }^{1}$ Department of Veterinary Science, University of Parma, Via del Taglio 10, 43126 Parma, Italy. ${ }^{2}$ Istituto Zooprofilattico Sperimentale della Lombardia e dell'Emilia Romagna, Via Bianchi 7/9, 25124 Brescia, Italy. ${ }^{3}$ Arcispedale S. Maria Nuova, Viale Risorgimento 80, 42123 Reggio Emilia, Italy. ${ }^{4}$ Clinica Veterinaria Malpensa, Via Marconi 27, 21017 Samarate, VA, Italy.

\section{Acknowledgements}

Not applicable.

\section{Competing interests}

CSC is one of the inventors in Italian patent on AMP2041: N. 102012902114114 (MI2012A002263). The patent was purchased by ICF s.r.l., Cremona, Italy. This company had no influence on the study design or the content of this manuscript.

\section{Availability of data and materials}

All data generated or analysed during this study are included in this published article.

\section{Funding}

This study was self-funded.

Received: 21 July 2016 Accepted: 18 March 2017

Published online: 23 March 2017

\section{References}

1. Davies JC. Pseudomonas aeruginosa in cystic fibrosis: pathogenesis and persistence. Paediatr Respir Rev. 2002;3(2):128-34.

2. Haenni M, Hocquet D, Ponsin C, Cholley P, Guyeux C, Madec J, et al. Population structure and antimicrobial susceptibility of Pseudomonas aeruginosa from animal infections in France. BMC Vet Res. 2015;11(9):1-5.

3. Boucher HW, Talbot GH, Bradley JS, Edwards JE, Gilbert D, Rice LB, et al. Bad bugs, no drugs: no ESKAPE! An update from the Infectious Diseases Society of America. Clin Infect Dis. 2009;48(1):1-12. 
4. Magiorakos AP, Srinivasan A, Carey RB, Carmeli Y, Falagas ME, Giske CG, et al. Multidrug-resistant, extensively drug-resistant and pandrug-resistant bacteria: an international expert proposal for interim standard definitions for acquired resistance. Clin Microbiol Infect. 2012;18(3):268-81.

5. Mesaros N, Nordmann P, Plesiat P, Roussel-Delvallez M, Van Eldere J, Glupczynski Y, et al. Pseudomonas aeruginosa: resistance and therapeutic options at the turn of the new millennium. Clin Microbiol Infect. 2007;13(6):560-78.

6. European commission. Communication from the commission to the European Parliament and the Council. Action plan against the rising threats from antimicrobial resistance. http://ec.europa.eu/dgs/health food-safety/docs/communication_amr_2011_748_en.pdf. Accessed 24 Feb 2017.

7. Oyston PC, Fox MA, Richards SJ, Clark GC. Novel peptide therapeutics for treatment of infections. J Med Microbiol. 2009;58(8):977-87.

8. Cabassi CS, Taddei S, Cavirani S, Baroni MC, Sansoni P, Romani AA. Broad-spectrum activity of a novel antibiotic peptide against multidrugresistant veterinary isolates. Vet J. 2013;198(2):534-7.

9. Romani AA, Baroni MC, Taddei S, Ghidini F, Sansoni P, Cavirani S, et al. In vitro activity of novel in silico-developed antimicrobial peptides against a panel of bacterial pathogens. J Pept Sci. 2013;19(9):554-65.

10. European Centre for Disease prevention and Control/European Medicines Agencies (ECDPC/EMA) ECDC/EMEA Joint Technical report. Stockholm: ECDPC/EMA; 2009. The bacterial challenge: time to react. A call to narrow the gap between multidrug-resistant bacteria in the EU and the development of new antibacterial agents.

11. Cabassi CS, Taddei S, Cavirani S, Sala A, Santospirito D, Baroni MC, et al. Antimicrobial activity of 4 novel cyclic peptides against a panel of reference and multi-drug resistant clinical strains of animal origin Pakistan. Vet J. 2015;35(4):522-4.

12. Cerceo EDS, Sherman BM, Amin AN. Multidrug-resistant Gram-negative bacterial infections in the hospital Setting: overview, implications for clinical practice, and emerging treatment options. Microb Drug Resist. 2016;22(5):412-31.

13. Chaparro-Barrios C, Ciancotti-Oliver L, Bautista-Rentero D, Adán-Tomás C, Zanón-Viguer V. A new treatment choice against multi-drug resistant Pseudomonas aeruginosa: doripenem. J Bacteriol Parasitol. 2014;5(5):1-4

14. Tommasi RBD, Walkup GK, Manchester JI, Miller AA. ESKAPEing the labyrinth of antibacterial discovery. Nat Rev Drug Discov. 2015;14(8):529-42.

15. Obritsch MD, Fish DN, MacLaren R, Jung R. Nosocomial infections due to multidrug-resistant Pseudomonas aeruginosa: epidemiology and treatment options. Pharmacotherapy. 2005;25(10):1353-64.

16. Liu XBD, Thungrat K, Aly S. Mechanisms accounting for fluoroquinolone multidrug resistance Escherichia coli isolated from companion animals. Vet Microbiol. 2012;161(1-2):159-68.

17. Gibson JSMJ, Cobbold RN, Filippich LJ, Trott DJ. Risk factors for multidrugresistant Escherichia coli rectal colonization of dogs on admission to a veterinary hospital. Epidemiol Infect. 2011;139(2):197-205.
18. Scott-Weese J. Antimicrobial resistance in companion animals. Anim Health Res Rev. 2008;9(2):169-76.

19. European Medicines Agency, Committee for Medicinal Products for Veterinary Use. Reflection paper on the risk of antimicrobial resistance transfer from companion animals. http://www.ema.europa.eu/docs/ en_GB/document_library/Scientific_guideline/2015/01/WC500181642. pdf. Accessed 24 Feb 2017.

20. Savini V, Passeri C, Mancini G, luliani O, Marrollo R, Argentieri AV, et al. Coagulase-positive staphylococci: my pet's two faces. Res Microbiol. 2013;164(5):371-4.

21. Hwang PMVH. Structure-function relationships of antimicrobial peptides. Biochem Cell Biol. 1998;76:235-46.

22. Yeaman MRYN. Mechanisms of antimicrobial peptide action and resistance. Pharmacol Rev. 2003;55(1):27-55.

23. Zhou C, Qi X, Li P, Chen WN, Mouad L, Chang MW, et al. High potency and broad-spectrum antimicrobial peptides synthesized via ring-opening polymerization of alpha-aminoacid- $\mathrm{N}$-carboxyanhydrides. Biomacromolecules. 2010:11(1):60-7.

24. Andreu D, Merrifield RB, Steiner H, Boman HG. Solid-phase synthesis of cecropin A and related peptides. Proc Natl Acad Sci U S A. 1983;80(21):6475-9.

25. Agerberth $B$, Lee JY, Bergman $T$, Carlquist $M$, Boman $H G$, Mutt $V$, et al. Amino acid sequence of PR-39. Isolation from pig intestine of a new member of the family of proline-arginine-rich antibacterial peptides. Eur J Biochem. 1991;202(3):849-54.

26. Saikia K, Sravani YD, Ramakrishnan V, Chaudhary N. Highly potent antimicrobial peptides from $\mathrm{N}$-terminal membrane-binding region of $E$. coll MreB. Sci Rep. 2017;7:42994

27. Oliver A, Cantón R, Campo P, Baquero F, Blázquez J. High frequency of hypermutable Pseudomonas aeruginosa in cystic fibrosis lung infection. Science. 2000;288(5469):1251-4.

28. Sousa A, Pereira M. Pseudomonas aeruginosa diversification during Infection development in cystic fibrosis lungs - a review. Pathogens. 2014;3(3):680-703.

29. Ge Y, MacDonald DL, Holroyd KJ, Thornsberry C, Wexler H, Zasloff M. In vitro antibacterial properties of pexiganan, an analog of magainin. Antimicrob Agents Chemother. 1999;43(4):782-8.

30. Varkey J, Nagaraj R. Antibacterial activity of human neutrophil defensin HNP-1 analogs without cysteines. Antimicrob Agents Chemother. 2005:49(11):4561-6.

31. Cudic M, Otvos L Jr. Intracellular targets of antibacterial peptides. Curr Drug Targets. 2002;3(2):101-6.

\section{Submit your next manuscript to BioMed Central and we will help you at every step:}

- We accept pre-submission inquiries

- Our selector tool helps you to find the most relevant journal

- We provide round the clock customer support

- Convenient online submission

- Thorough peer review

- Inclusion in PubMed and all major indexing services

- Maximum visibility for your research

Submit your manuscript at www.biomedcentral com/submit 